\title{
BMJ Open Young people's perceptions of accessing a community pharmacy for a chlamydia testing kit: a qualitative study based in North East England
}

\author{
Lara Ahmaro (D) , ${ }^{1}$ Laura Lindsey, ${ }^{2}$ Simon Forrest, ${ }^{3}$ Cate Whittlesea ${ }^{4}$
}

To cite: Ahmaro L, Lindsey L, Forrest S, et al. Young people's perceptions of accessing a community pharmacy for a chlamydia testing kit: a qualitative study based in North East England. BMJ Open 2021;11:e052228. doi:10.1136/ bmjopen-2021-052228

- Prepublication history and additional supplemental materia for this paper are available online. To view these files, please visit the journal online (http://dx.doi.org/10.1136/ bmjopen-2021-052228).

Received 08 April 2021 Accepted 26 August 2021

Check for updates

(c) Author(s) (or their employer(s)) 2021. Re-use permitted under CC BY-NC. No commercial re-use. See rights and permissions. Published by BMJ.

${ }^{1}$ Population Health Sciences Institute, Newcastle University, Newcastle upon Tyne, UK ${ }^{2}$ School of Pharmacy and Population Health Sciences Institute, Newcastle University, Newcastle upon Tyne, UK ${ }^{3}$ College of St Hild \& St Bede, and Sociology Department, Durham University, Durham, UK

${ }^{4}$ Research Department of Practice and Policy, University College London, School of Pharmacy, London, UK

Correspondence to

Lara Ahmaro;

L.Ahmaro2@Newcastle.ac.uk

\section{ABSTRACT}

Objectives Chlamydia testing among young people in community pharmacies in North East England has been low compared with other remote settings offering testing for the past few years. To understand why this may be, to maximise service provision, the perceptions of young men and women about pharmacy testing and possible chlamydia treatment were gathered and interpreted. Design Indepth, semistructured interviews. Setting Four youth centres in North East England. Participants The study included 26 young people aged 16-23. The sample of participants comprised those with a history of chlamydia testing as well as those never tested. Interviews Face-to-face interviews were conducted between October 2018 and May 2019. The interview schedule covered young people's perceptions of sexually transmitted infections, provision of pharmacy sexual and reproductive health and chlamydia testing, and potential chlamydia treatment. Data from the interviews were subjected to thematic analysis.

Results The geographical accessibility and long opening times of community pharmacies in North East England were perceived benefits of the service. However, young people had concerns about being judged by pharmacy staff or overheard by customers when requesting the test. Men did not want to be seen by their peers accessing the pharmacy. These barriers were associated with a perceived stigma of chlamydia. Despite this, young people thought that pharmacist advice on the test kit would be important to ensure they complete it correctly. Those never tested favoured how the kit could be taken home to complete the urine sample. The option of including chlamydia treatment was reported to be convenient and comforting.

Conclusion Supporting pharmacies in North East England to offer a confidential chlamydia testing service is necessary to overcome young people's perceived barriers to testing. Delivering testing as an integrated sexual health package with other pharmacy services, together with treatment where suitable, will increase acceptance for testing and timely access to treatment.

\section{INTRODUCTION}

Chlamydia is the most common bacterial sexually transmitted infection (STI) in England $^{1}$ and globally. ${ }^{2}$ As most individuals
Strengths and limitations of this study

- From interviews, this study provides an indepth understanding into the factors associated with a young person's decision not to access a community pharmacy for chlamydia testing.

- The sample of young people interviewed included those who have never been tested for chlamydia as well as young men, who access pharmacy testing less than women, to investigate how the service can appeal to these groups.

- Young people were recruited from areas in North East England; the study findings and proposals to promote pharmacy chlamydia testing are targeted at local practice rather than nationally.

- Demographic parameters of education level and relationship status were not gathered, the inclusion of which could be used to create a more diverse sample.

with the infection are asymptomatic, it is often left untreated, increasing the risk of transmission and serious health consequences in both sexes. ${ }^{3}$ To reduce these risks, screening for chlamydia is implemented in several countries and regions including the USA, Switzerland, England, Australia, Belgium, Sweden and Norway. ${ }^{4-6}$

Chlamydia prevalence is greatest among young people aged $15-24$ years. ${ }^{1}$ To reach this age group, the NHS in England delivers a national chlamydia screening programme which recommends that young people test for STI each year and on change of sexual partner. ${ }^{1}{ }^{7}$ Under the programme, health and non-healthcare settings, including sexual health services, general practices, community pharmacies, internet, and schools and colleges, offer free chlamydia testing for young people to increase detection and treatment of STI. ${ }^{17}$ The delivery of testing differs between the settings; sexual health services and some general practices can manage symptomatic individuals, which 
may incorporate a genital examination and urogenital swab or first catch urine, while community pharmacies and internet-based postal testing manage asymptomatic cases by swab or urine sampling. ${ }^{8}$ More specifically, under commissioning agreement with local authorities, pharmacies that choose to deliver the service provide a free postal testing kit accompanied with sexual health advice. ${ }^{9}$ Young people request the kit and complete the urine sample at home before posting it for testing. Pharmacists can also offer the kit during a consultation for the emergency contraceptive pill (ECP) - the provision of a contraceptive tablet to women to reduce the risk of unintended pregnancy after unprotected sex; and the condom card (C-Card) scheme-free condom supplies to young people on presenting the C-Card ${ }^{9}$ From their findings, the authors of a recent retrospective study suggested that providing several sexual health services including STI testing in one pharmacy visit promoted service uptake, particularly among young people. ${ }^{10}$ Depending on local agreement, pharmacies may also be commissioned to offer free treatment for chlamydia as part of the testing service if a young person is found to be positive for STI. ${ }^{9}$

It is well documented that the convenient location and long opening hours of pharmacies make them accessible to deliver testing. ${ }^{611-14}$ Nevertheless, in North East England, where many pharmacies are commissioned to deliver free testing, ${ }^{1516}$ uptake of the test kit in this setting has been low for the past few years compared with other venues managing asymptomatic cases, including internetbased testing. ${ }^{17}$ Furthermore, uptake among young men is less than women. Clients of pharmacy testing in previous studies felt comfortable to speak with the pharmacist and favoured their non-judgemental approach. ${ }^{11} 1314$ However, some of these respondents, and clients in other studies, had mixed feelings about the pharmacy environment, citing privacy and embarrassment concerns with requesting the testing kit as main barriers..$^{611-14} 18$

Further investigation is necessary to understand why uptake of pharmacy chlamydia testing is low in North East England. By studying the perceptions of those who have and also those who have never been tested for chlamydia, a rich insight would be gathered into the experience of testing and how the pharmacy service can appeal to more young people. At the time of this study, in the region, free treatment for chlamydia was not part of the locally commissioned pharmacy testing service. Views on whether the potential addition of treatment may impact testing activity should also be examined. Of note, this paper is part of a larger study which also investigated pharmacists' views on pharmacy chlamydia testing, enhancing the solidarity of the findings. Their views are planned to be published.

In this study, individual, semistructured interviews were conducted with young people with the aim to investigate their perceptions of chlamydia, of accessing a pharmacy for a testing kit and of potential treatment provision with testing, to understand how to promote the service.

\section{METHODS}

\section{Sampling and recruitment}

Between October 2018 and May 2019, young people were recruited in four youth centres in North East England to participate in indepth, semistructured interviews about their perceptions of the pharmacy chlamydia testing service. The youth centres were in proximity to community pharmacies offering the chlamydia testing kit. Purposive sampling was selected to recruit the participants based on the following criteria: aged 16-24, English-speaking, young people who have been tested for chlamydia in a healthcare/non-healthcare setting, and young people who have not been tested. The exclusion criterion was young people who did not have the capacity to consent to taking part in the study.

The youth centres were initially identified for recruitment by accessing the online directories of the study sites, which provided information and links to youth centre websites. Youth workers at the centres were approached by the first author and informed about the study aim and objectives and planned method of conducting the interviews. At least twoweeks prior to the interviews, youth workers at the centres disseminated participant information leaflets and consent forms to young people for consideration. The first author then visited eight different weekly group sessions regularly delivered by the youth centres providing a range of activities. These sessions comprised approximately 45 young people in total. The first author introduced herself and presented the reason for the study and proposed interviews to the attendees and recruited 26 who were happy to participate and fitted the sampling criteria. Sixteen attendees declined to participate; their reasons were not gathered. Of note, the first author is a pharmacist by profession who emphasised her role as a researcher to the participants in investigating chlamydia testing; she continually noted and reflected on her involvement at each recruitment and interview.

All but one session were visited once; the remaining session was visited twice to allow the first author sufficient time to conduct the interviews with all those interested. The group sessions were in areas of varying socioeconomic profiles to gather and compare views and experiences where sexual health outcomes may be different; the location of each session was mapped to the Indices of Multiple Deprivation 2015. ${ }^{19}$ Then, a deprivation quintile for each location was calculated, representing areas in the most deprived 20\% of England as quintile 1 to areas in the least deprived $20 \%$ as quintile 5 . The sessions were in areas assigned to quintiles 1,2 and 4 .

\section{Data collection}

During the group session, each participant was interviewed by the first author in a quiet area of the youth centre for confidentiality. First, the participant information sheet and then the consent form were summarised. The participant was assessed for their capacity to consent to participate through their understanding about the 
study and interview process and ability to communicate their decision about taking part. The participant was reminded of their right to withdraw from the study. The interview schedule, which was developed from review of the existing literature on pharmacy chlamydia testing, covered young people's perceptions of STIs, pharmacy provision of sexual health and chlamydia testing, and potential inclusion of chlamydia treatment within the testing service (see online supplemental material 1). It was planned to last approximately 20-30 min, and comprised 20 questions, 15 of which were open-ended. A task-based activity was also included where participants read three statements on cards written in first person and expressed whether they agreed to them and why. This provided them with the space to explore their views covering specific topic areas. After the interviews, the next steps of the study and reminder of entitlement to withdraw were explained. Participants were then given a $£ 10$ gift voucher in recognition of their contribution. Following each interview, the first author noted the key thoughts and ideas raised by the participant and the dynamics of the discussion.

\section{Data analysis}

All the interviews were audio-recorded with participants' permission. On average, they lasted 20min (range 13-32 min). Each recording was then transcribed verbatim by the first author, quality-checked and anonymised, and the recording destroyed. Ideas were gathered from each transcript and the interviews were continued until the first author found that no additional material was identified during the preliminary data analysis and the data began to repeat. ${ }^{20}$ The transcripts were entered into a computer-assisted analysis software NVivo V.11 Pro (QSR International, 2015). Data from responses to closed-ended questions were interpreted into a table for analysis. Thematic analysis was applied to analyse the remaining data, ${ }^{21}$ the data underwent inductive coding, and the codes were collated to form themes, which were reviewed against the coded extract and the data set. This led to an indepth interpretation of the factors surrounding the perceived barriers to chlamydia testing. Accounts of participants with and without chlamydia testing experience were analysed separately and the results were then compared; accounts that differed between the groups were highlighted in the reporting of the results. During analysis, to minimise researcher bias, all authors individually coded a selection of transcripts, which were then shared and discussed with one another during regular meetings. The codes were then revisited by the first author across the entire data set to check that they were consistent and accurate. All authors also collectively reflected on the developing themes in relation to the codes to ensure that the meaning of the data was accurately interpreted.

\section{Patient and public involvement}

A total of 25 representatives from a young people's advisory group and a youth organisation were involved in the study design and dissemination of the findings. They were
Table 1 Demographic details of participants interviewed

\begin{tabular}{lc}
\hline \multicolumn{2}{l}{ Variables } \\
\hline Age (years), mean \pm SD & $18.8 \pm 1.9$ \\
Gender, $\mathrm{n}(\%)$ & $16(61.5)$ \\
$\quad$ Male & $10(38.5)$ \\
\hline Female & $6(54.5)$ \\
Setting tested for chlamydia/test kit obtained ${ }^{*} \mathrm{n}(\%)$ \\
Sexual health clinic & $2(18.2)$ \\
Community pharmacy & $1(9.1)$ \\
College & $1(9.1)$ \\
General practice & $1(9.1)$ \\
Multiple test settings & 13 \\
\hline Deprivation area & 7 \\
Quintile 1 & 4 \\
\hline Quintile 2 & \\
\hline Quintile 4 & \\
\hline
\end{tabular}

The table lists the demographic details of the 26 participants interviewed in the study. From these participants, 10 had a history of being tested for chlamydia and 16 had never been tested. Under Deprivation area, quintiles 1, 2 and 4 indicate the locations of the recruitment sites within areas in the most to least deprived in England.

*One participant was tested for chlamydia at a sexual health clinic, community pharmacy and college.

of the same age range as those in the proposed sampling frame and included both women and men; the number of each gender was not recorded. At the study design stage, the groups reviewed the topic areas of the interview schedule (see online supplemental material 1), advised on the effective methods for communicating with young people about sexual health, and evaluated the participant information leaflet and consent form for clarity. At the dissemination stage, the advisory group reviewed the content and format of the summary of findings leaflet prior to its distribution to the youth groups for participants' feedback on the findings.

\section{RESULTS}

Twenty-six young people aged 16-23 were recruited in the study. From these participants, 10 had a history of being tested for chlamydia and 16 had never been tested. Table 1 lists the demographic details of the participants interviewed.

Five key themes were synthesised from the interviews: worry about chlamydia, pharmacy location and opening times, attributes of a healthcare professional, privacy and confidentiality for young people, and information about chlamydia testing.

\section{Worry about chlamydia}

When participants were asked what sexual health and STIs meant to young people, most reported that both they and other young people were worried if peers found 
out they had an STI or chlamydia or were being tested, in case peers made negative comments: 'You get judged quite a lot, like, nowadays. So, like, if somebody found out you'd be labelled as disgusting or, like, something' (P15, female). Some young people at one location mapped to deprivation quintile 1 reported that the negative social consequences of chlamydia were a particular concern in their area.

Many young people said that they were unsure what the symptoms of chlamydia were or its potential adverse health complications if left untreated. Nevertheless, some of these participants said that its effects on the body, and whether it could be treated or not, was a worry.

\section{Pharmacy location and opening times}

When asked whether they knew if there was a pharmacy local to them, most young people reported that they lived within walking distance of a pharmacy which they said was convenient for them. Some added that the long opening times and weekend opening hours were helpful for accessibility:

They [pharmacies] do, like, late erm.... I think it's a Wednesday they close later on. So, obviously if it's a younger person who could go after school maybes, or if you're at work and you're working late you can go. Or you could go before school or before work because they're open quite early. (P4, female)

However, a few young people said that pharmacies were crowded places. Some added that having to wait for a prescription was inconvenient. Others felt that a busy pharmacy impacted the degree of privacy and hence confidence they felt to request a service or a testing kit.

When asked their views on the option of treatment with the pharmacy testing service, many felt it would be helpful because 'it's in the same place. If it's local and it's convenient too...once you've found out if you have it [chlamydia], you can get it sorted, and get it treated' (P2, male).

\section{Attributes of a healthcare professional}

When young people were asked how they would feel if the pharmacist counselled them on the chlamydia testing kit, most said that they felt it was important to ensure they completed it correctly and carefully to prevent it from going wrong:

With the pharmacy, as long as they explained in depth because again it is a serious matter so if they, like, said one... one... one thing that was, like, not understood properly and then the test could go wrong. It's, like, detail's the best thing to go into. (P12, male)

In addition, those who saw a pharmacist for a sexual or reproductive health service said that they were happy with the service they received as the information provided was clear to follow: the pharmacist 'made me feel at ease' (P25, female) and that the staff were 'lovely over there' (P14, female). However, participants who received the
ECP either reported that they declined the kit or did not complete it once they took it home. Many others who were asked their thoughts if offered the chlamydia testing kit alongside a supply of the ECP or C-Card said that they were unsure that they would want it and reported that their primary concern would be to receive the requested service. Most participants who did obtain a pharmacy chlamydia testing kit said either that they had minimal or no communication on how to use it, but that the service was quick and easy.

Some young people said that they thought they might be judged by the pharmacist or support staff on requesting the testing kit. Most of these participants said that they would not access the pharmacy in case there were staff who 'can't talk to people, like, my age. Someone, like, who looks down on you' (P11, female). They suggested that pharmacists and support staff should be welcoming and friendly, offer young people options with regard to their care, and not 'make it feel like there's a massive elephant in the room' (P5, male). Most young men reported that they would attend alone for the testing kit.

Of those who were tested in settings other than pharmacies, such as sexual health clinics and general practices, most reported that they knew the healthcare professionals and the method of testing delivered. They added that such familiarity was convenient and reassuring for them.

Some women reported that, if treatment for chlamydia was part of the pharmacy testing service, it would mean that 'you don't have to go to two separate places and then two people, like...two places know about it, sort of thing. It's just one' (P16, female). They felt that returning to the same pharmacist was easier than accessing a different setting.

\section{Privacy and confidentiality for young people}

Some young people were unaware of the availability of pharmacy consultation rooms. These young people strongly believed that a private area was necessary, like at general practices and sexual health clinics, so that support staff and customers would not hear their conversation with the pharmacist.

Some men said that they thought they might be seen and judged by their peers if they entered the pharmacy:

If I go to a pharmacy, it's like 'What are you going in there for?' Someone might see me going in and question why, and that. Obviously, if you've got, like, chlamydia and that, you don't want to tell everyone really, do you? You might feel insecure about it. (P22, male).

There were mixed feelings on taking the testing kit home. Some participants who were never tested reported that they would obtain a pharmacy testing kit as they said they felt it would be easy to complete at home in their own time. However, a few younger participants said that they were concerned in case a family member found the kit. 


\section{Information about chlamydia testing}

Most young people said that they knew about the pharmacy ECP and C-Card services, but only some about pharmacy chlamydia testing. Many perceived that awareness of the pharmacy testing service was low among youth and that it should be promoted at schools and colleges and on social media platforms. A few men said that the sexual health clinic was the main setting they would attend if they thought about testing for STIs, as they were aware of the services provided there:

When you think sex you think, err, STIs, you might go straight to a clinic. You wouldn't-... and I'm not quite sure what the pharmacy could put in place for them to make people aware that pharmacy is also a place where you can go for chlamydia screening tests and that. (P9, male)

\section{DISCUSSION}

\section{Principal findings}

Despite the geographical accessibility and long opening hours of community pharmacies, this paper provides an indepth insight into why young people might not be accessing the setting for a chlamydia testing kit.

A key finding of this study was the role played by young people's concerns about stigma in obstructing uptake of testing for chlamydia, which is consistent with the literature. ${ }^{22-25}$ Furthermore, this paper adds to studies where young people had privacy concerns about the pharmacy environment ${ }^{6121418}$ and about other comparable settings for testing, including general practice ${ }^{26}$ and non-medical venues, ${ }^{27}$ by suggesting that the concern is linked to perceived stigma. While young people in the present study who used a pharmacy sexual health service and chlamydia testing were happy with the service, promotional activities should also focus on young people who felt uncomfortable in accessing the pharmacy and young men, due to privacy and stigma concerns. To overcome these perceived barriers, the convenience of pharmacy consultation rooms and provision of a welcoming, nonjudgemental service should be promoted ${ }^{28}$ and measures to facilitate a young person's request for the kit considered; the availability of a form or card indicating this request is an option, similar to that of the C-Card. Previous research found that young people experienced the C-Card scheme to be confidential and easily accessible in non-medical settings. ${ }^{29}$ Of significance, the present study found that young people from an area of high deprivation perceived that chlamydia was particularly stigmatising in their region. This suggests that different socioeconomic contexts may be linked to STI testing behaviour, as shown in previous studies. ${ }^{30}{ }^{31}$ Nonetheless, accounts on the perceived barriers to pharmacy testing were comparable across the sites.

Another key finding was that, although young people perceived they may be judged on requesting the testing kit, they felt that pharmacist advice on how to use it was important in supporting them to complete it correctly. This is similar to findings from a study on young people's views on testing in general practice who preferred the guidance of a healthcare professional on how to selfsample for chlamydia. ${ }^{26}$ Furthermore, where young people in the present study had concerns about whether STIs could be treated or not, the option of returning to the same pharmacist to obtain chlamydia treatment was both convenient and reassuring for them. Therefore, a potential pharmacy test-and-treat service may encourage further uptake compared with testing alone. Recognition of such pharmacist advice and support strengthens the expanding role of pharmacists as advocates in sexual health. Additionally, when young people access the pharmacy for services such as the ECP and C-Card, pharmacists should offer comprehensive information and advice on STIs to encourage them to rationalise their risk of the infection. ${ }^{32}$ Where suitable, extending the offer of the kit with other pharmacy sexual health products, treatments and advice may present further opportunity for testing as part of an integrated sexual health package.

Young people who had not been tested for chlamydia favoured how the testing kit could be taken home to complete a urine sample. This adds to the findings of a study by Lorimer and McDaid, ${ }^{33}$ where young men found home self-testing ordered online to be acceptable, and to research by Wilson $e t a l,{ }^{34}$ who showed that test kits posted to young people's homes for completion increased testing activity among those who were previously never tested. Furthermore, in the present study, there was a low perceived awareness of the pharmacy testing service. Similarly, McDonagh $e t a l^{26}$ found that some young people in their study were unaware of testing in general practice. This finding, together with preference for home-sampling, highlights that greater targeted advertising of testing in pharmacy and indeed other comparable settings may be necessary. It should include promoting the ease and convenience with which the testing kit can be completed and, within pharmacy, the availability of the pharmacist for advice, where clients in previous research found such support to be helpful. ${ }^{11}{ }^{14}$ This advice should be offered at every opportunity, as users in the present study reported receiving no or minimal information about the kit. Additionally, young people's suggestion of social media advertising of pharmacy testing in the present study adds to the findings by Nadarzynski $e t a l,{ }^{35}$ who showed that this method of advertising, linked to internet-based chlamydia testing, increased service uptake in the age group.

\section{Strengths and limitations}

A strength of this study is that it not only identified young people's perceived barriers to accessing a pharmacy in North East England for a chlamydia test, but it also gathered their accounts of how social and emotional factors can inhibit such access. This facilitated the development of robust proposals to address these factors to increase testing activity. Second, the first author was mindful that, from her professional status as a pharmacist, maintaining 
a wholly objective stance to the data collection and analysis may be particularly challenging. As such, measures were taken to reduce risk of researcher involvement; the first author continually reflected on her role to minimise influencing participants' accounts or interpretation of the findings. Here, writing fieldnotes both during and after each interview and discussing these and the emerging findings during regular meetings with all authors helped to minimise bias. One limitation is that the recommendations proposed to maximise testing were targeted at local practice, rather than nationally. Therefore, their transferability to processes involved in pharmacy testing across other regions of England must be carefully assessed. Second, demographic parameters of education level and relationship status were not gathered in the sampling frame, the inclusion of which could be used to create a more diverse sample. Third, while the first author employed several strategies to reduce risk of participation bias, 16 young people declined to take part in the study without stating why. Gathering their reasons for non-participation and brief demographic information may have helped to assess whether their views were likely to differ or not from those recruited.

\section{Policy implications and further work}

This study's findings support Public Health England's report on pharmacy delivery of sexual and reproductive health ${ }^{9}$ by highlighting the following: the need for further integration of the chlamydia service with other sexual health provisions to increase testing opportunity and discussions around STIs; and to offer chlamydia treatment within the service where suitable, which may reduce perceived worry about whether chlamydia can be treated. Furthermore, this paper presented similarities in findings to previous research on testing in other comparable settings, mainly associated with privacy and stigma concerns. Therefore, it can be hypothesised that measures to overcome such barriers as suggested in the present study may support service promotion in those settings where applicable.

In England in 2018, the impact of chlamydia and STIs was highest among young heterosexual men and women, men who have sex with men, and black ethnic minorities, highlighting an inequality in sexual health. ${ }^{1}$ To help address this inequality, future work should also recruit participants spanning these demographic groups, where the sample is representative of the broader population of those at high risk of chlamydia; findings from these groups may contribute to chlamydia testing, detection and prevention.

\section{CONCLUSION}

This study provides an insight into why young people in North East England may not be accessing a community pharmacy for chlamydia testing. They perceived pharmacies to be geographically accessible to them and favoured if treatment for the infection was included in the testing service. However, due to the stigma of chlamydia, they had privacy and judgement concerns about obtaining a chlamydia test from the setting. Furthermore, there was a low perceived awareness about pharmacy testing and staff provided minimal or no information on the test kit to those who used the service. These factors highlight the following measures are necessary to promote pharmacy chlamydia testing: to deliver and advertise a young people-friendly testing service, with treatment provision as a more comprehensive package where suitable; to offer advice on chlamydia, recommendations on when to test and correct completion of the test kit at every opportunity; and to promote the availability of pharmacy consultation rooms and facilitate a young person's request for the test kit. Such measures will help to maximise service delivery, contributing to greater chlamydia testing in the region.

Acknowledgements Many thanks to all the participants who took part in the study and to the advisory groups for their guidance in the study design and dissemination stages of the research. We also thank the reviewers for their careful review of the manuscript and helpful comments.

Contributors With guidance and support from LL, SF and CW, LA designed the study as part of her PhD research and undertook the data collection and analysis of the data. LL, SF and CW also coded a selection of transcripts which were then shared and discussed. All authors reflected on the themes as they developed in relation to the data set. LA prepared the manuscript, and the draft versions were critically reviewed by LL, SF and CW. All authors approved the final manuscript.

Funding This work was supported by the Harold and Marjorie Moss Charitable Trust (UK) (DFH/19986), covering the dissemination costs of the findings.

Competing interests None declared.

Patient consent for publication Not required.

Ethics approval This study was approved by the Newcastle University Faculty of Medical Sciences Ethics Committee (approval reference number 1603/6935/2018).

Provenance and peer review Not commissioned; externally peer reviewed.

Data availability statement All data relevant to the study are included in the article or uploaded as supplementary information.

Supplemental material This content has been supplied by the author(s). It has not been vetted by BMJ Publishing Group Limited (BMJ) and may not have been peer-reviewed. Any opinions or recommendations discussed are solely those of the author(s) and are not endorsed by BMJ. BMJ disclaims all liability and responsibility arising from any reliance placed on the content. Where the content includes any translated material, BMJ does not warrant the accuracy and reliability of the translations (including but not limited to local regulations, clinical guidelines, terminology, drug names and drug dosages), and is not responsible for any error and/or omissions arising from translation and adaptation or otherwise.

Open access This is an open access article distributed in accordance with the Creative Commons Attribution Non Commercial (CC BY-NC 4.0) license, which permits others to distribute, remix, adapt, build upon this work non-commercially, and license their derivative works on different terms, provided the original work is properly cited, appropriate credit is given, any changes made indicated, and the use is non-commercial. See: http://creativecommons.org/licenses/by-nc/4.0/.

ORCID iD

Lara Ahmaro http://orcid.org/0000-0001-5202-0204

\section{REFERENCES}

1 Mitchell $\mathrm{H}$, Hester A, Sonubi T. Sexually transmitted infections and screening for chlamydia in England, 2019. London: Public Health England, 2020.

2 Rowley J, Vander Hoorn S, Korenromp E, et al. Chlamydia, gonorrhoea, trichomoniasis and syphilis: global prevalence and incidence estimates, 2016. Bull World Health Organ 2019;97:548-62. 
3 Nwokolo NC, Dragovic B, Patel S, et al. 2015 UK national guideline for the management of infection with Chlamydia trachomatis. Int $J$ STD AIDS 2016;27:251-67.

4 European Centre for Disease Prevention and Control. Chlamydia control in Europe-a survey of member states. Stockholm: European Centre for Disease Prevention and Control, 2014. https://www.ecdc. europa.eu/sites/default/ files/media/en/publications/Publications/ chlamydia-control-survey-europe-2012.pdf

5 Workowski KA, Bolan GA. Sexually transmitted diseases treatment guidelines. 64. Atlanta: Centers for Disease Control and Prevention, 2015.

6 Arnet I, Gudka S, Salter S, et al. Readiness of pharmacists and consumers for pharmacy-based chlamydia screening in Australia and Switzerland. Sex Reprod Healthc 2018;16:138-53.

7 Public Health England. National chlamydia screening programme standards. 7th edn. London: Public Health England, 2018. https:// www.gov.uk/government/uploads/system/uploads/attachment_data/ file/477343/NCSP_Standards_7th_edition_FINAL.pdf

8 British Association for Sexual Health and HIV. Standards for the management of sexually transmitted infections (STIS). Cheshire: British Association for Sexual Health and HIV, 2019. https://www. bashh.org/media/4429/bashh-standards-for-sti-management-2019. pdf

9 Public Health England. The pharmacy offer for sexual health, reproductive health and HIV: a resource for commissioners and providers. London: Public Health England, 2019.

10 Gauly J, Atherton H, Kimani PK, et al. Utilisation of pharmacy-based sexual and reproductive health services: a quantitative retrospective study. Sex Transm Infect 2021;97:126-33.

11 Baraitser P, Pearce V, Holmes J, et al. Chlamydia testing in community pharmacies: evaluation of a feasibility pilot in South East London. Qual Saf Health Care 2007;16:303-7.

12 Taylor KL, Clifford RM, Marshall L. Acceptance of a Chlamydia Screening Program in Community Pharmacies. J Pharm Pract Res 2007;37:287-91.

13 Gudka S, Marshall L, Creagh A, et al. To develop and measure the effectiveness and acceptability of a pharmacy-based chlamydia screening intervention in Australia. BMJ Open 2013;3:e003338.

14 Parker RM, Bell A, Currie MJ, et al. 'Catching Chlamydia': combining cash incentives and community pharmacy access for increased Chlamydia screening, the view of young people. Aust J Prim Health 2015;21:79-83.

15 NHS. Find pharmacy services, 2018. Available: https://www.nhs.uk/ service-search/pharmacy

16 Pharmaceutical Services Negotiating Committee. Pharmaceutical services negotiating committee pharmacy services spreadsheet, 2021. Available: https://psnc.org.uk/wp-content/uploads/2021/04/ Services-Spreadsheet-Updated-16.04.21.xlsx [Accessed Apr 2021].

17 Public Health England. Chlamydia testing data in 15-24 year olds, England, 2015-2019 [online], 2020. Available: www.gov.uk/ government/statistics/national-chlamydia-screening-programmencsp-data-tables [Accessed Jan 2021].

18 Brugha R, Balfe M, Jeffares I, et al. Where do young adults want opportunistic chlamydia screening services to be located? J Public Health 2011;33:571-8.

19 Department for Communities and Local Government. The English indices of deprivation 2015. London: Department for Communities and Local Government, 2015. https://www.gov.uk/government/ uploads/system/uploads/attachment_data/file/465791/English_ Indices_of_Deprivation_2015_-_Statistical_Release.pdf

20 Kerr C, Nixon A, Wild D. Assessing and demonstrating data saturation in qualitative inquiry supporting patient-reported outcomes research. Expert Rev Pharmacoecon Outcomes Res 2010;10:269-81.

21 Braun V, Clarke V. Using thematic analysis in psychology. Qual Res Psychol 2006;3:77-101.

22 Balfe M, Brugha R, O'Connell E, et al. Why don't young women go for Chlamydia testing? A qualitative study employing Goffman's stigma framework. Health Risk Soc 2010;12:131-48.

23 Balfe M, Brugha R, O'Connell E, et al. Men's attitudes towards chlamydia screening: a narrative review. Sex Health 2012;9:120-30.

24 Theunissen KATM, Bos AER, Hoebe CJPA, et al. Chlamydia trachomatis testing among young people: what is the role of stigma? BMC Public Health 2015;15:1-8.

25 Richardson D, Maple K, Perry N, et al. A pilot qualitative analysis of the psychosocial factors which drive young people to decline chlamydia testing in the UK: implications for health promotion and screening. Int J STD AIDS 2010;21:187-90.

26 McDonagh LK, Harwood H, Saunders JM, et al. How to increase chlamydia testing in primary care: a qualitative exploration with young people and application of a meta-theoretical model. Sex Transm Infect 2020;96:571-81.

27 Lorimer K, Reid ME, Hart GJ. "It has to speak to people's everyday life": qualitative study of men and women's willingness to participate in a non-medical approach to Chlamydia trachomatis screening. Sex Transm Infect 2009;85:201-5.

28 Department of Health. Quality criteria for young people friendly health services [online]. London: DOH, 2011. https://assets.publishing. service.gov.uk/government/uploads/system/uploads/attachment data/file/216350/dh 127632.pdf

29 Kinsella K, Cross R, South J. An evaluation of the condom distribution scheme (C-Card) with young people in northeast England. Perspect Public Health 2014;134:25-30.

30 Booth AR, Norman P, Harris PR, et al. Using the theory of planned behavior to identify key beliefs underlying Chlamydia testing intentions in a sample of young people living in deprived areas. $\checkmark$ Health Psychol 2015;20:1229-39.

31 Woodhall SC, Soldan K, Sonnenberg P, et al. Is Chlamydia screening and testing in Britain reaching young adults at risk of infection? Findings from the third national survey of sexual attitudes and lifestyles (Natsal-3). Sex Transm Infect 2016;92:218-27.

32 Allen L. 'They Think You Shouldn't be Having Sex Anyway': Young People's Suggestions for Improving Sexuality Education Content. Sexualities 2008;11:573-94.

33 Lorimer K, McDaid L. Young men's views toward the barriers and facilitators of Internet-based Chlamydia trachomatis screening: qualitative study. J Med Internet Res 2013;15:e265.

34 Wilson E, Leyrat C, Baraitser P, et al. Does internet-accessed STI (e-STI) testing increase testing uptake for chlamydia and other STIs among a young population who have never tested? Secondary analyses of data from a randomised controlled trial. Sex Transm Infect 2019;95:569-74.

35 Nadarzynski T, Burton J, Henderson K, et al. Targeted advertisement of chlamydia screening on social media: a mixed-methods analysis. Digit Health 2019;5:205520761982719. 